\title{
Encruzilhadas de um corpo pós-colonial: f(r)icção arte/vida na cena contemporânea
}

Crossroads of a postcolonial body: $f(r)$ iction art/life in the contemporary scene

Daniel Santos Costa

Sayonara Sousa Pereira ${ }^{2}$ 


\section{Resumo}

Este artigo apresenta uma breve reflexão fruto dos processos vivenciados no Programa de Pós-Graduação em Artes da Cena na Universidade Estadual de Campinas - UNICAMP, entre 2012 e 2014. Desse lugar, onde é possível dimensionar um discurso autoral, visto sob uma perspectiva pós-colonial aliada ao percurso teórico-prático na criação da cena contemporânea $O$ presente texto apresenta parte de um processo de formação e criação de um artista que $f(r)$ iccionou arte-vida para entender um percurso singular. As perspectivas aqui trabalhadas partem de um ponto de vista autoral sobre como o corpo-sujeito buscou a entrecruzar experiências e processos como um caminho de pesquisa.

Palavras-chave: Corpo; cena contemporânea; conhecimento; encruzilhadas; experiência.

\section{Abstract}

This paper presents a brief reflection result of processes lived at the Postgraduate Program in Arts Scene at the State University of Campinas - UNICAMP between 2012 and 2014. In this place, where you can dimension an authorial speech, viewed from a postcolonial perspective combined with theoretical and practical way in the creation of the contemporary scene. This paper presents part of a process of formation and creation of an artist in $f(r)$ iction art / life to understand a singular way. The perspectives here worked starting from an authoral viewpoint about how the bodysubject experiments sought interlacing and processes as a search trajectory.

Keywords: Body; contemporary scene; knowledge; crossroads; experience.
ISSN: 1414.5731

E-ISSN: 2358.6958
1 Doutorando em Artes Cênicas - Universidade de São Paulo (USP). Docente no curso de Artes/Teatro da Universidade Estadual de Montes Claros (UNIMONTES). Pesquisador do LAPPET (CNPq), PINDORAMA (CNPq) e do coletivo artístico BONITA grdcosta@gmail.com

2 Profa. Dra. e pesquisadora da Escola de Comunicações e Artes - Departa- mento de Artes Cênicas da Universidade de São Paulo (ECA/USP). Doutora e pós Doutora pelo IA/UNICAMP, e especialista em Dança pela Folkwang Hochschule -Essen/Alemanha. Dirige o LAPETT (Laboratório de Pesquisa e Estudos em Tanz Theatralidades ) na ECA/USP. sayopereira@usp.br 
$\mathrm{Na}$ tentativa de profanar estratégias de um pensamento autoral recorro ao presente texto para uma discussão sobre a produção cultural, em especial àquela voltada para as artes cênicas sob uma perspectiva da margem ou na tentativa de nela se localizar. O posicionamento do sujeito num determinado lugar implica, antes de mais nada, um estudo aguçado, pois nós, indivíduos, sujeitos, grupos e instituições pósmodernas estamos imbricados de modo dinâmico num intenso processo de contaminações, de rupturas, de des-centramentos que nos impedem de agarrar à qualquer categoria identitária.

Quem é o sujeito que profana? De onde ela fala? Qual é o seu discurso? Como ele pronuncia o mundo através da sua produção artística? Estas são perguntas, por mais retóricas que possam projetar-se, são pontos de partida para uma possível (des) organização epistemológica que, como sujeito, busco provocar. No caminho em que recorro a tais interrogações desenvolvo esta produção pautada na investigação do processo criativo como produção de conhecimento - e autoconhecimento.

Debati-me inúmeras vezes com a ordem do pensamento dominante imperativo no ambiente acadêmico. Como sujeito oriundo de classe social baixa, nascido no interior de Minas Gerais, residente na zona rural grande parte da infância e adolescência, manifestante de Folias de Reis, integrante do Movimento de Luta pela Terra 3 , trago no corpo que sou experiências que passam, que me tocam e produzem reverberações. Essas características arraigadas destoavam, por exemplo, da formação cultural das alunas da turma do curso de dança, em que iniciei em 2006 na Universidade Estadual de Campinas. Outro fator marginal à ordem dessa formação foi o fato de ser único homem a ingressar no respectivo ano, o que proporcionava outro descentramento.

Único homem e não oriundo de uma formação tecnicista rígida alceei voos formativos na própria ideia do corpo (em) processo, que num alinhavo bastante intuitivo possibilitou uma formação preciosa, singular. Busco, nesse trajeto, estratégias íntegras, um caminho possível é um olhar para si, para identidade, memórias pessoais, autobiografia para o exercício de uma atitude reflexiva que considere o valor das condições subjetivas do conhecimento como abertura para novos questionamentos científicos.

Greiner (2010), pesquisadora da comunicação e das artes do corpo apoiada no discurso do filósofo italiano Giorgio Agamben vem corroborando esse discurso das singularidades não categorizado por escolas técnicas, gêneros ou temas. Há o prelúdio de que é necessária uma mudança paradigmática, que podem ser pensadas como singularidades, focados nas diferenças e na construção de epistemologias locais.

Deparo-me então, ao olhar para minha biografia (autobiografia), com a ideia de identidade observando as mudanças tratadas por Hall (2011) e ocorridas no pensamento moderno acerca de sujeito e identidade. $O$ autor trabalha com visão de descentramento ${ }^{4}$ do sujeito, o que sugere que poderíamos falar melhor em identificação do que em identidade, por trazer um entendimento de processo em andamento, 0

3 MST - Movimento dos Sem Terra, ou MLT - desmembramento do movimento no estado de Minas Gerais, que mais tarde intitulou-se MLST - Movimento de Luta dos Sem Terra.

4 Stuart Hall trabalha com a noção de descentramento considerando a importância da leitura das obras de Marx, Freud, Saussure, Foucault e a questão do Feminismo, onde em cada um desse ligara à problematização e/ou reinvindicação de uma identidade própria deslocando o sujeito de uma visão cartesiana. 
que corrobora com minha acepção de um corpo (em) processo.

Assim, articulo esse "Eu" com a proposta do jamaicano Stuart Hall como uma possibilidade de desarticular estabilidades e possibilitar o surgimento de novas identidades, que, em sua visão, são abertas, contraditórias, plurais e fragmentadas, caracterizando o sujeito pós-moderno, onde a identidade tornou-se uma espécie de "festa móvel"; descentradas, deslocadas, híbridas, de uma complexidade dialética.

Hall (2011) traz uma importante reflexão no sentido de entender um caminho possível, pois observa que em direção à homogeneização há uma fascinação pela diferença. Há, juntamente com o impacto "global", um novo interesse pelo "local" que repensa novas articulações entre essas duas categorias. Esse "local" não deve, naturalmente, ser confundido com velhas identidades, firmemente enraizadas em localidades bem delimitadas" (Hall, 2011, p.77-78).

A globalização, nesses aspectos estaria vinculada à tentativa de uniformização, homogeneização, mas é preciso olhar à margem e perceber que, ao mesmo tempo em que dissolve barreiras, aproxima o centro e a periferia imediata (e intensamente) e isso pode restaurar a presença do marginalizado (Bhabha, 2011) num estado de emergência, de vir à tona, ou da possibilidade do sujeito de vir a ser.

Há o desejo de contrapor dispositivos de sujeição dos indivíduos às diretrizes do poder que giram no vazio em direção a um abismo catastrófico. Nessa contemporaneidade, busco enxergar o escuro desse tempo, e não apenas as luzes, no intuito de descobrir o meu escuro especial que não é, no entanto, separado das luzes, conforme a reflexão de Agamben (2009, p. 64):

Ao contrário, o contemporâneo é aquele que percebe o escuro do seu tempo como algo que the concerne e não cessa de interpretá-lo, algo que mais do que toda a luz, dirige-se direita e singularmente a ele. Contemporâneo é aquele que recebe em pleno rosto o facho de trevas que provém do seu tempo.

Então, "nos fachos das trevas que provém do meu tempo", resolvo profanar minhas experiências para discutir através do corpo a minha política, meu modo de existir, de pensar. Aproximo-me da periferia do pensamento dominante, onde, aliás, localizo-me geograficamente. Vejo o mundo como sou, na perspectiva do corpo-espaço e percepção que essas experiências agregadas podem pronunciar. Entretanto, sou sujeito dialógico enxergando-me no entrelugar, uma possibilidade para o híbrido. Percebo o mundo em analogia às impressões da cultura popular, não apenas àquela voltada às espetacularidades, mas aos movimentos populares - periféricos. Estes se mantêm na fricção entre arte/vida de modo menos binário e encontramse num movimento muito mais dinâmico que os olhares encharcados pelas teorias estrangeiras que tanto nos apetecem como sociedade pós-colonial, também situado na sociologia do corpo apontada por Le Breton (2006). Mantenho, com olhos atrevidos, uma possível dialogia entre o conhecimento produzido na academia e o conhecimento popular, seus modos de fazer-saber-pensar, estando no entrelugar: dentro-fora, margem-centro...

O antropólogo latino-americano Canclini (2011) problematiza a seguinte questão alicerçada também no pensamento sobre hibridismo defendido por Hall (2011): Como analisar as manifestações que não cabem no culto ou no popular, que brotam 
de seus cruzamentos ou em suas margens? Para o autor é necessário um olhar diferenciado para olhar as culturas híbridas para desfazer ordens habituais e deixar que emerjam as rupturas e justaposições que poderão culminar num discurso interessado no saber, em outro tipo de organização de dados. Nesse lugar é preciso dar ênfase e quebra e mescla dos sistemas culturais, a desterritorialização dos sistemas simbólicos e a expansão dos gêneros impuros (Canclini, 2011, p.284).

Ao falar das culturas híbridas no contexto a América Latina, Canclini (2011) lança mão da ideia de hibridação cultural nesses países. Com tal conceito, o autor busca entender melhor o entrelaçamento cultural em que nos inserimos, e, de modo interdisciplinar, aponta as estratégias, as contradições e fracassos da nossa modernização, problematizando também as relações entre a tradição e a modernidade, numa complexa rede. Um exemplo fundamental são as transformações geradas pelas tecnologias, na produção e circulação simbólica não atrelada somente aos meios de comunicação. Essas transformações, produzidas pelo entrecruzamento de inúmeros vetores da modernidade, justificação dos embaraços e suas crises, colocam em questão uma preocupação para Canclini.

A principal ausência nos trabalhos de folclore é não questionar sobre o que ocorre com as culturas populares quando a sociedade se massifica. $\mathrm{O}$ folclore, que surgiu na Europa e na América como reação frente à cegueira aristocrática para com o popular e como réplica à primeira industrialização da cultura, é quase uma tentativa melancólica de subtrair o popular à reorganização massiva, fixa-lo nas formas artesanais de produção e comunicação, custodiá-lo como reserva imaginativa de discursos políticos nacionalistas (2011, p. 213).

Longe da ideia de uma visão e de discursos nacionalistas estanques, reorganizo formas espetaculares da cultura popular brasileira, em sua práxis no dinamismo da criação artística. Observar, por exemplo, as Folias de Reis inseridas no contexto urbano, na cidade de Campinas, interior de São Paulo, demonstra aptidão de um acesso da margem ao centro. Inseridas num contexto urbano, a manifestação hibridiza suas ações rituais num espaço/tempo deslocado da sua característica intrínseca, a ruralidade, estando em constante movimento diferentemente de um senso comum que denominam as tradições populares por caráter de pureza cultural e essencialismo ao passado como um lugar distante.

Então, num entrelugar, vislumbro e localizo-me nesse lugar simbólico do qual se processam vias diversas de elaboração discursiva, motivadas pelos próprios discursos que o coabitam. Corpo-sujeito-artista-pesquisador, localizo-me à margem de alguns imperativos da sociedade capitalista num movimento de pertencimento à cultura tradicional e à cultura de massa urbana. Oriundo de um universo típico das Folias de Reis no interior de Minas Gerais e Goiás, aliados ao universo mítico e ritualístico vivenciados em acampamentos de Sem-Terra, de alguém que reside na periferia do espaço urbano contemporâneo, tomo o corpo como um lugar de experiência, em que confluem todos esses lugares para amálgama da minha dissertação político -artística. Encaro-me, desse modo, como um novo sujeito criado em "entrelugares", formado geralmente, segundo Bhabha (2007), do que sobra daquilo que foi pré-definido (raça, gênero, classe). 
Nesse lugar, o pensamento do estudioso indiano faz como que a dimensão das minorias (ou suas experiências) esteja produzindo efeitos de mudanças na ideia de cultura nacional abarcando não apenas uma retomada ou releitura do passado, mas uma renovação da atuação do presente, revelando as assimetrias paradigmáticas da produção artística contemporânea. Pretendo, assim, introduzir a invenção, como também define Manoel de Barros (2008) dentro da possibilidade da existência, por meio da experiência da formação artística (em) processo (em) criação e suas encruzilhadas.

Revelar ou desvelar a identidade através do corpo e inventar-iar nesse percurso permite, num contexto mais amplo, perceber a atuação de um corpo-sujeito a partir de sua condição de entrecruzamento, impulsionando desejáveis ações inter e transdisciplinares na pesquisa nas artes da cena. Nessa instância, do não nomeado, marcado pela impermanência, desejo estar nessas encruzilhadas, em entrelugares, questionando na ação os modos de fazer categorizados que transformam a obra artística em produto de mercado ou dominados por discursos dominantes.

Nesse sentido, ancoro também relação com o pensamento do Professor Boaventura de Souza Santos, da Universidade de Coimbra - Portugal sobre as Epistemologias do Sul e do Norte. Há saberes hegemônicos dominantes e precisamos atentar para epistemologias alternativas que rompam paradigmas e privilegiem o novo, novos modos de fazer. Santos (2008) critica então, a epistemologia positivista enquanto paradigma dominante nas Ciências, propondo a existência de uma crise nessa perspectiva epistemológica, entretanto, acompanhada da emergência de um novo paradigma.

As Epistemologias do Sul defendidas por Santos (2008) não são necessariamente geográficas, e sim, no sentido de perceber o discurso dominante e o dominado - pelo capitalismo, pela sociedade patriarcal e colonialista. Assim sendo, o pesquisador defende a ideia da interdisciplinaridade. Uma ruptura com a ideia de disciplina, como compartimento fechado e isolado, torna-se necessária. A sociedade apresenta uma multiplicidade complexa de vozes que chegam ao sujeito ditando ordens, regras, modelos, padrões, conceitos e ideias, e que, a partir do caminho da interligação e inter e/ou transdisciplinaridade, é possível viabilizar uma reorganização desse sujeito. Assim temos a interdisciplinaridade criando novas realidades, já que nascem da proposição de novos objetivos, de novos métodos, cuja tônica primeira é a supressão do monólogo vazio e a instauração de dialogias, traço evidente no processo que lançarei olhar nesta segunda parte segunda parte, o espetáculo Ô de Casa? Ô de Fora! ou a história do homem que pediu uma Folia a Pombagira Cigana, de minha autoria e direção de Grácia Navarro.

Volto atenção, então, às tessituras do processo do espetáculo Ô de Casa? Ô de Fora! ou a história do homem que pediu uma Folia à Pombagira Cigana $(2014)^{5}$, onde tive a oportunidade de projetar o mundo a partir de fragmentos da minha autobiografia advindo de tensões entre linguagens cênicas, como a dança e o teatro; das linguagens visuais, como figurinos, ambientes e iluminação; e da linguagem musical em

5 Espetáculo criado durante pesquisa de mestrado desenvolvida no Programa de Pós-Graduação em Artes da Cena na Universidade Estadual de Campinas sob a orientação da Profa. Dra. Grácia Navarro, entre 2012 e 2014. 
sonoridades do corpo, intervenções musicais editadas e ao vivo, a partir do diálogo com a oralidade popular brasileira.

As cores, as sonoridades e as texturas das espontaneidades e espetacularidades da cultura popular brasileira estão presentes em minha memória e arraigadas/ inscritas em meu corpo. Eu era uma criança de pouco falar, mas os outros sentidos extrapolavam muitas vezes a rotineira percepção comum. Os sons, os cheiros, os gostos, as imagens e a percepção tátil ainda prevalecem e dominam a entidade que sou corpo. Nesse lugar de observador, percebo um mundo infindável das percepções que repercutem ainda nas francas vivências nesse lugar do Brasil.

As Folias de Reis (essencialmente rurais) permeiam minhas recordações de infância. As festividades populares como as festas de reis, as festas juninas e outros rituais de festividades populares têm presença marcante na memória, deixaram rastros ou os fiapos, como dizia minha avó. Festas de reis, festas juninas, personagens-tipo, paisagens do cerrado são elementos que carrego no corpo. Inserido num ambiente extremamente rural até grande parte de minha adolescência, é a partir desse lugar que são impressas as qualidades de movimento que danço. Dançar quadrilha, encenar o casamento caipira, participar de procissões, romarias, vigílias religiosas, campanhas comunitárias em diversos espaços são memórias sempre retomadas em dança.

As vivências no interior do Brasil, em Minas Gerais, Goiás, as típicas paisagens do cerrado incrustaram no corpo em movimento e são transformadas em dança a partir da investigação que se dá através do próprio corpo. É o corpo em movimento quem vai dando o tom deste trabalho. A partir das escavações das memórias em laboratórios coreográficos, vou buscando modos de pensar que possam, não explicar, mas dialogar com os conteúdos trazidos na prática e nas experiências.

As experiências de vida, bem como os traços autobiográficos que essas vivências trazem inscritas no corpo que sou, implicam modos específicos de pensar-fazer, de se colocar em relação à criação reverberada em traços arquétipos que estão arraigados nesse corpo e numa postura integrada ao mundo circundante. Assim, desdobro minha autobiografia em movimento, em sonoridades, em visualidades transcriadas em poética da cena.

Minhas memórias não se encaixam em pedaços de papel. Reside em mim infindável mundo de percepções vivenciadas num tempo extremamente mítico e ritualístico que pode ser a vida no interior do Brasil. Em um movimento de integração, por um modo de vida longe de alguns imperativos da sociedade contemporânea, sistematizando a minha história em dança, revelando pedaços de mim em espirais, mostrando minha relação com o mundo.

Escolhi o movimento para dar sentido à vida. É em movimento que vou costurando de ponto em ponto, em linhas curvas e sinuosas, a minha dança. Busco, nesta medida, epistemologias que possam complexamente dialogar com a minha breve história de vida e o movimento em cena, dançado, experienciando. Entender a Folia de Reis no corpo é trajeto que almejei, investigando as histórias que nele estão, numa poética da linguagem autobiográfica na cena contemporânea, na encruzilhada (entrelugar), realidade-ficção, arte-vida.

Busco, nesse trajeto, estratégias íntegras para o novo, e considero que um caminho possível é um olhar para si, para identidade, memórias pessoais, autobiografia 
para o exercício de uma atitude reflexiva que considere o valor das condições subjetivas do conhecimento como abertura para novos questionamentos científicos como me estimulou Klauss Vianna em suas observações e elucubrações das infâncias registradas no livro A Dança, conforme trecho abaixo:

\begin{abstract}
Observações. Hora observando os pés. Os meus e os dos outros. As marcas que deixavam na areia ou no cimento, quando saiam da piscina. O joelho foi o mais difícil: quase sempre o lado escondido das pessoas. As costas, comprimento dos braços, o jeito da cabeça. A expressão, os olhos, boca, nariz. As mãos. Abrir a mão para apanhar. Lembrança da dor. A casa: não só grande. Enorme. Sempre fechada $(2005$, p. 23$)$.
\end{abstract}

Do mergulho na autobiografia e num movimento individual ao coletivo, percebi que o exercício da alteridade é elemento essencial na construção ou pensamento sobre identidade. Durante o processo de criação da referida obra integrei o Grupo Pindorama6, um espaço de investigação cênica das espetacularidades da cultura brasileira à produção teatral na contemporaneidade. As experiências vivenciadas ali foram deglutidas a ponto de influenciar toda a primeira ideia de processo, bem como a proposta de dramaturgia e um posicionamento político-artístico que o fazer-pensar a obra artística proporcionou.

O processo culminou num espetáculo de linguagem híbrida, refletindo seu processo criativo que reuniu, nos laboratórios de criação, a competência para o devir da experiência processual. Travei diálogo entre manifestações da cultura nacional e matrizes culturais díspares para um pensamento do hibridismo, ou mesmo do sincrético, típico da construção de uma possibilidade de ser brasileiro, como a Umbanda e Folias de Reis.

A Umbanda, além de fazer parte da gênese da personagem central, possui uma linguagem que influencia o espetáculo estruturalmente. A dinâmica de incorporação e desincorporação, característica da chegada e partida de uma entidade no corpo do filho de santo, é recriada no espetáculo, demarcando a troca de personagens que se desdobram do personagem central na condução da ação narrativa.

A Folia de Reis traz a vida pessoal do autor, amalgamando com afeto o binômio vida/arte que demarca a pesquisa empreendida. Na Folia, está o lugar da reunião mítica do autor com seus antepassados ancestrais e próximos. Essas manifestações foram tomadas como elementos da cultura brasileira e adquirem o status de "material". Esses "materiais" foram friccionados no território conceitual e experimental da "encruzilhada" - espaço relacional primordial do novo, da mestiçagem e da liminaridade. Dessa fricção houve a extração de uma dramaturgia ficcional, comprometida com a percepção estética e com o jogo cênico, limitada a um ponto de vista dentre a multiplicidade de possibilidades que tais materiais certamente suscitam.

Umbanda e Folias de Reis são duas manifestações observadas em sua teia urbana para um diálogo que incide sobre o espaço da cidade e as reverberações desses contatos nas paisagens do corpo em cena. Antagônicas, contudo, apresentam traços de um sincretismo típico da formação brasileira, em que diferentes das noções de

6 PINDORAMA da espetacularidade popular brasileira à produção teatral na contemporaneidade. Grupo de Pesquisa - CNPq coordenado pela Profa. Dra. Grácia Maria Navarro. 
popular tradicional encontram-se num movimento incessante para a manutenção de suas performances-rituais no espaço urbano.

$\mathrm{Na}$ Umbanda, esse espaço é mais visível, pois trata-se de manifestações mais urbanas. Vem se desenvolvendo, desde a década de 1930, no cenário brasileiro, num contexto de intensos sincretismos entre "tradições religiosas africano-brasileiras e com o espiritismo Kardecista francês" (Prandi, 1996, p. 2), também pautado por Martins (1997), sob a caracterização de que "a umbanda é um exemplar desse registro sincrético, fundindo em seu tecido cognitivo e ritual, elementos de outros sistemas religiosos nagô, banto, católico, tupi-guarani, kardecista, espírita numa reformulação sui generis" (/bidem, 1997, p. 14). Essa aglutinação umbandista, uma fusão sistêmica, vem ao encontro de uma perspectiva da formação da sociedade brasileira, mestiça, híbrida, limiar.

O sincretismo acontece, então, na encruzilhada, um lugar simbólico no qual se processam vias diversas de elaboração discursiva, motivadas pelos próprios discursos que a coabitam. Operadora de linguagens e de discursos, a encruzilhada, como um terceiro lugar, ou como um entrelugar definido por Bhabha (2011) é geratriz de produção sígnica, diversificada e, portanto, de sentidos. Nesse espaço, noções de sujeito híbrido, mestiço e liminar, articuladas pela crítica pós-colonial podem ser pensadas como indicativos dos efeitos de processos e cruzamentos discursivos diversos, intertextuais e interculturais.

Essa encruzilhada possibilita a emergência de desdobramentos possíveis, caracterizados por sua natureza móvel e deslizante, no movimento da cultura e dos saberes ali instituídos. Ou seja, essa definição nos oferece a possibilidade de interpretação do trânsito sistêmico e epistêmico que emerge dos processos inter ou transculturais, nos quais se confrontam e dialogam, nem sempre amistosamente, registros, concepções e sistemas simbólicos diferenciados, como reflexo da complexidade da vida. De acordo com Martins:

Da esfera do rito, portanto da performance, é lugar radial de centramento e descentramento, intersecções e desvios, textos e tradução, confluências e alterações, influências e divergências, fusões e rupturas, multiplicidade e convergência, unidade e pluralidade, origem e disseminação (1997, p. 28).

As Folias de Reis alteram seus espaços rituais, desde as décadas de 1960 e 1970, em virtude do êxodo rural como Costa (2010) percebeu em um estudo etnográfico na cidade de Campinas - SP. O deslocamento do lugar ritual do campo para a cidade provoca na manifestação um descentramento, contudo esta apresenta um poder de adaptação ao novo espaço demonstrando uma grande aptidão que combate dualismos positivistas numa constante evolução entre homem e ambiente, natureza e sociedade, sagrado e profano.

Longe da ideia de uma visão e de discursos nacionalistas estanques, reorganizamos formas espetaculares da cultura popular brasileira, em sua práxis no dinamismo da criação artística. Observar, por exemplo, as Folias de Reis inseridas no contexto urbano, na cidade de Campinas, interior de São Paulo, demonstra aptidão de um acesso da margem ao centro. Colocadas em tal espaço, a manifestação hibridiza suas ações rituais num espaço/tempo deslocado da sua característica intrínseca, a rura- 
lidade, estando em constante movimento diferentemente de um senso comum que denomina as tradições populares por caráter de pureza cultural e essencialismo em relação ao passado como um lugar distante.

As Folias de Reis e a Umbanda são manifestações paradoxais que extrapolam a noção de estranhamento do artista em campo, e aproximam-se de um contexto de origem, de um brasileiro que frequenta tais espaços e faz parte das paisagens desses lugares. Percorremos os giros de Folias de Reis pela cidade de Campinas e as giras de Umbanda em regiões periféricas dessa mesma cidade entre os anos de 2006 até 2014 e dessa experiência resultou a obra Ô de Casa? Ô de fora! ou a história do homem que pediu uma Folia a Pombagira Cigana resultou em um espetáculo de linguagem híbrida, refletindo seu processo criativo que reuniu nos laboratórios de experimentação prática a competência das áreas das Artes da Cena - Teatro e Dança; das Artes Visuais - figurinos, ambientes e iluminação; da Música - sonoridades e repertório da oralidade popular brasileira. O hibridismo, aqui amalgamado, tem uma singularidade que ainda busca uma nomeação quanto ao gênero cênico, porque também na constituição da linguagem, guarda a encruzilhada na fusão e ruptura das suas linguagens de origem: Dança e Teatro, conforme release apresentado na temporada de estreia, em 2014.

\begin{abstract}
O espetáculo acontece na encruzilhada da realidade com a ficção da vida de um homem que transita entre os afazeres do seu cotidiano e o passado que se faz presente na memória de situações da casa da família e para fora dela. A casa é o corpo? Ou o corpo é a casa? Um Corpo-Casa como um lugar no mundo e como o próprio mundo, revelando um território sem limite entre a realidade cotidiana e uma realidade paralela, habitada por personagens e situações míticas colhidas na oralidade popular brasileira e na autobiografia do bailarino/ator. Fruto de pesquisa empírica, o espetáculo resulta em uma escritura de linguagem híbrida que alia recursos da dança e do teatro às artes visuais e à música. Dessa aliança, emerge um espetáculo de dança-teatro, instigante e misterioso, que tem o jogo entre ficção e realidade como eixo transversal da sua dramaturgia. Nesse jogo-encruzilhada entre a realidade e a ficção, é narrada a história de um homem que pediu uma Folia à Pomba Gira Cigana e sua aventura na espera e no pagamento do pedido prometido?
\end{abstract}

Nessa perspectiva, reforço a apropriação dos aspectos pessoais e coletivos vivenciados nas manifestações da cultura popular brasileira para problematizar, ou ainda, descentrar o lugar discursivo e disciplinar por onde as questões dominantes de identidade são estrategicamente colonizadas, reconhecendo a interioridade num ato de comunidade e alteridade.

Projetando-me nesse lugar, lanço olhares a mim, como corpo-sujeito das próprias experiências e da minha dança, através da abordagem de um corpo próprio, um corpo que dança encarnado em seu contexto histórico e social explorando a multivocalidade e a polissemia, entendendo o corpo como processo (em) criação, não segmentado, entre a "carne do mundo" e a "carne do homem", uma realidade mutante para nossa lógica aristotélica ocidental. Assim, buscou-se a possibilidade de ajudar a dar voz às comunidades e processos marginalizados onde, no recorte das

7 O espetáculo foi premiado pelo Fundo de Investimentos Culturais de Campinas (FICC 2013/2014) e cumpriu temporada de estreia em diversos espaços da cidade de Campinas entre Fevereiro e Março de 2014. 
experiências pessoais, possamos reclamar de modo menos submisso, quiçá subversivo, por nossa produção de conhecimento, muitas vezes vista sob uma névoa ou um vidro embaçado.

Os aspectos acima pontuados vêm corroborar com a ideia de um pluralismo epistemológico que possa alargar perspectivas, assumir a experiência como práxis abrindo pontes para os saberes menosprezados, marginalizados e estigmatizados por uma visão teórica legitimadora de algumas as formas de expressão.

Esse pensamento vai ao encontro da visão de buscar outras epistemologias, as do Sul de Santos (2008), que sempre provoca-me a pensar que outras formas de conhecimentos são possíveis e contrárias aos paradigmas dominantes que a ciência moderna postula. Reafirmo, desse modo, a posição de Fabrini (2013, p. 11) acerca da "urgência do reconhecimento do saber sensível enquanto episteme". A autora, propondo uma ideia de um possível cena do sul, recorreu à Boaventura de Souza Santos para alicerçar seu pensamento acerca dessa visão, nos propondo uma ideia de saberes do sul.

Quais seriam esses saberes invisibilizados por essa hegemonia e o que teriam eles a ver com o teatro? Eu diria que são os saberes que nascem da experiência de estar no mundo, da abertura aos afetos (o constante deixar-se afetar) e, portanto um modo de estar no mundo ancorado, enraizado na totalidade complexa do corpo - e isso é estar em cena! Corpo que, em primeira instância, é natureza, mas uma natureza "almada" (Fabrini, 2013, p. 16).

Nos, brasileiros carregamos o resultado do mix cultural, ou sincretismo atravessando velhas fronteiras, que não é o cultivo do velho pelo novo, mas a busca de alternativa híbridas, sintetizando elementos de todas as raízes interculturais e intertextextuais. Paradoxais, contraditórios, (des)ritmados e irregulares, os traços da mudanças culturais podem produzir resistências ou o fornecimento de especifidades locais para o engajamento de uma cena que venha da experiência, da fricção arte-vida e que possa desabrochar em produção de conhecimento. Esse reconhecimento pontua de modo insistente nossa práxis, através do corpo em sua totalidade.

É preciso da margem ir ao centro, para que o centro experimente a margem celebrando de modo instintivo as diferenças. Desse deslocamento, podemos pensar um local específico através do qual, nas teorias contemporâneas, podemos repensar as regras estabelecidas do jogo instaurado. As velhas concepções não contam com as explicações e projeções do mundo, assim como sonhos marcados pela utopia da homogeneização. Precisamos almejar uma produção cultural intrigante e paradoxal, harmoniosa nas diferenças. É a vez e a hora de escavar esse entrelugar (encruzilhadas), as fissuras entre os conceitos, enxergando o híbrido, marcando o discurso da diferença que tornar-se-á ponto de partida, um ato transgressor, uma condição do pensamento à margem de um indivíduo autor e autônomo.

\section{Referencias}

AGAMBEN, Giorgio. O que é o contemporâneo e outros ensaios. Chapecó: Argos, 2013. 
BARROS, Manoel. Poesia Completa. São Paulo: Leya, 2010.

BHABHA, Homi K. O local da cultura. Belo Horizonte: Editora UFMG, 2011.

CANCLINI, N. G. Culturas híbridas: estratégias para entrar e sair da modernidade. São Paulo: EDUSP, 2011.

COSTA, Daniel S. Histórias e memórias de Folias de Reis. EGIL: Ituiutaba, 2010.

FABRINI, V. Sul da cena, sul do Saber. Moringa: artes do espetáculo, João Pessoa, João Pessoa, V. 4 N. 1 jan-jun/2013.

GREINER, C. O Corpo e suas paisagens de risco: dança/performances no Brasil. Anais do Il Congresso Nacional de Pesquisadores em Dança - ANDA, Porto Alegre, n. 2, p. 1-9, jul., 2012. Disponível em http://www.portalanda.org.br/anais. Acesso em 06 abr. 2014.

O corpo em crise: novas pistas e o curto-circuito das representações.

São Paulo: Annablume, 2010.

HALL, Stuart. A identidade na pós-modernidade. Trad. SILVA, Tomaz Tadeu \& LOURO, Guacira Lopes: Rio de Janeiro: DP\&A editora, 2006.

LARROSA, J. Notas sobre a experiência e o saber da experiência. Revista Brasileira de Educação. N. 19, p. 20-28, Jan/Fev/Mar/Abr/2002.

ORTIZ, Renato. Cultura brasileira e identidade nacional. São Paulo: Brasiliense, 2012.

A morte branca do feiticeiro negro: umbanda e sociedade brasileira. São Paulo: Brasiliense, 2011.

SANTOS, Boaventura de Souza (Org.). Epistemologias do Sul. São Paulo: Editora Cortez. 2010.

LE BRETON, David. A sociologia do corpo. 4 ed. Rio de Janeiro: Vozes, 2010.

MARTINS, Leda Maria. Afrografias da Memória. São Paulo: Perspectiva, 1997.

PRANDI, R. Pombagira e as faces inconfessas do Brasil. In: Herdeiros do Axé. São Paulo, Hucitec, 1996.

VIANNA, K. A dança. São Paulo: Sammus, 2005.

Recebido em: 24/10/2016

Aprovado em: 30/10/2016 